\title{
Silicone pressure-sensitive adhesives with increased thermal resistance
}

\author{
Adrian Krzysztof Antosik ${ }^{1} \cdot K_{\text {Karolina Mozelewska }}$ - Marta Piątek-Hnat ${ }^{2} \cdot$ Zbigniew Czech $^{1}$ (D) Marcin Bartkowiak ${ }^{1}$
}

Received: 4 November 2020 / Accepted: 20 August 2021 / Published online: 9 October 2021

(c) The Author(s) 2021

\begin{abstract}
The purpose of this work was to obtain single-sided tapes with different concentrations of kaolin and to check its impact on the self-adhesive properties of commercial adhesives. The most important self-adhesive properties were examined, such as tack, peel adhesion, shear strength, shrinkage, and thermal resistance. Tapes based on silicone PSAs with kaolin can be used in many branches of industry to bond elements operating at elevated temperatures, i.e., in aeronautics, aerospace including solar cells for satellites and space stations. There are few reports on one-sided adhesive tapes based on silicones with the addition of kaolin. However, taking into account the number of their potential applications, we did self-adhesive tests and explained how kaolin affects them. In addition, the reactivity of the crosslinking compound and silicone adhesive during the crosslinking process and the thermal effects of this process were also examined. In connection with the various applications of the obtained tapes, also the flammability and heat of combustion were tested, in accordance with applicable standards. As a result of the tests, one-sided self-adhesive tapes with new properties (increased temperature resistance, less shrinkage, and increased resistance to flammability) were obtained.
\end{abstract}

Keywords Kaolin $\cdot$ Silicone pressure-sensitive adhesives $\cdot$ PSA tapes $\cdot$ Thermally resistance $\cdot$ Processing technologies

\section{Introduction}

Pressure-sensitive adhesives (PSA) are adhesives with the ability to form the joint between bonded surfaces under low pressure. One of their advantages is the ability to detach the adhesive from the surface without leaving any traces [1]. Pressure-sensitive adhesives are viscoelastic materials, which remain permanently tacky at room temperature in a solvent-free state. PSAs should exhibit high cohesive strength to be able to join two surfaces without leaving marks. Mechanically, a PSA is a soft and sticky substance; thus, non-sticky support is often required to convert it into commercially useful forms (tapes, labels, etc.) [2, 3]. PSAs are also adhesives that form bonds under low pressure,

Zbigniew Czech

psa_czech@wp.pl

1 Department of Chemical Organic Technology and Polymeric Materials, West Pomeranian University of Technology, Pułaskiego 10, 70-322 Szczecin, Poland

2 Department of Polymer and Biomaterials Science, West Pomeranian University of Technology, Piastów Ave. 45, 70-311 Szczecin, Poland without activating by chemical reactions, heat, or radiation $[1,4]$. The main difference between pressure-sensitive adhesives and other types of adhesives lies in the fact that in the first case, the adhesive surface does not change its properties both before and after application [4].

In the 1960s, silicone adhesives were introduced to the market. Since then, many application options have been found. Some of the former PSA silicone applications are industrial operations (masking, joining, wrapping rolls), as well as electrical engineering and electronics, medical care and healthcare, and in the automotive sector. Since 2000, there has been an increase in interest in silicone PSAs, especially in applications such as medical and industrial tapes. The foregoing examples describe the growing range of potential commercial uses where silicone pressure-sensitive adhesives are being introduced [5-7]. Silicone pressure-sensitive adhesives are usually comprised of high-molecularweight silanol-functional silicone polymers and siloxane resins (MQ). It is well known that silicone-based adhesives are products for special applications. The combination of the unique properties of silicones, such as high flexibility of $\mathrm{Si}-\mathrm{O}-\mathrm{Si}$ backbone, low surface tension, low intermolecular interactions, high UV transparency, and excellent 
thermal stability, explains the growing interest in pressuresensitive adhesives manufacturers. That is why the silicone pressure-sensitive adhesives exhibit superior performance at high- and low-temperature conditions, excellent electrical properties, chemical resistance, and outstanding resistance according to weather conditions; it makes them superior compared to other PSAs [8-10].

In order to improve the properties of the adhesive, crosslinking is performed. There are various techniques of crosslinking: the addition of special compounds (multifunctional chemical $x$-linkers), thermal crosslinking, UV radiation, or electron beam, and many more [9]. In the present work, dichlorobenzoyl peroxide was used as a radical initiator. The crosslinking reaction of the silicone pressuresensitive adhesive is shown in Fig. 1.

Depending on the application of the resulting adhesive, they should have different properties. In the presented case, apart from high cohesive strength, thermal resistance is also important. Pressure-sensitive adhesives are used in various applications, also where high thermal resistance is required, along with maintaining self-adhesive properties. There are many literature and patent reports regarding adhesives with increased thermal resistance. This applies mainly to solvent-free adhesives and acrylic PSA [11]. High-temperature adhesives can be divided into two groups: inorganic adhesives (based on metal phosphates, activated carbon, etc.) and organic ones. The first of them are very resistant to heat, require special connection and have low internal strength. The second group is resistant to very high temperatures; however, these types of adhesives tend to maintain a cross-linked structure $[12,13]$. In many cases, activated carbon is described as a nanofiller that improves thermal resistance [14].

Kaolin is a mineral that comes from the Earth's crust. It was first found in China, and its name (Kao-Ling) means "high hill". Kaolin is an aluminum silicate with the formula: $\mathrm{Al}_{2} \mathrm{O}_{3} \cdot 2 \mathrm{SiO}_{2} \cdot 2 \mathrm{H}_{2} \mathrm{O}$. Kaolin formed in the Earth's crust as a result of hydrothermal weathering of rocks about 100 million years ago. Kaolin is one of the most important fillers. It is chemically inert and has many features that are desirable in various industries: plastics, coatings, wires, cables, in the paper industry, construction, or even in the cosmetics industry and agriculture [15, 16]. Literature shows that it is not only chemically inert, but also improves mechanical properties, thermal stability and flammability. It also has very good plasticity, high whiteness, easy dispersion, large specific surface, and is a very good electrical insulator. Undoubtedly, a very big advantage of kaolin is its low price compared to other fillers [17].

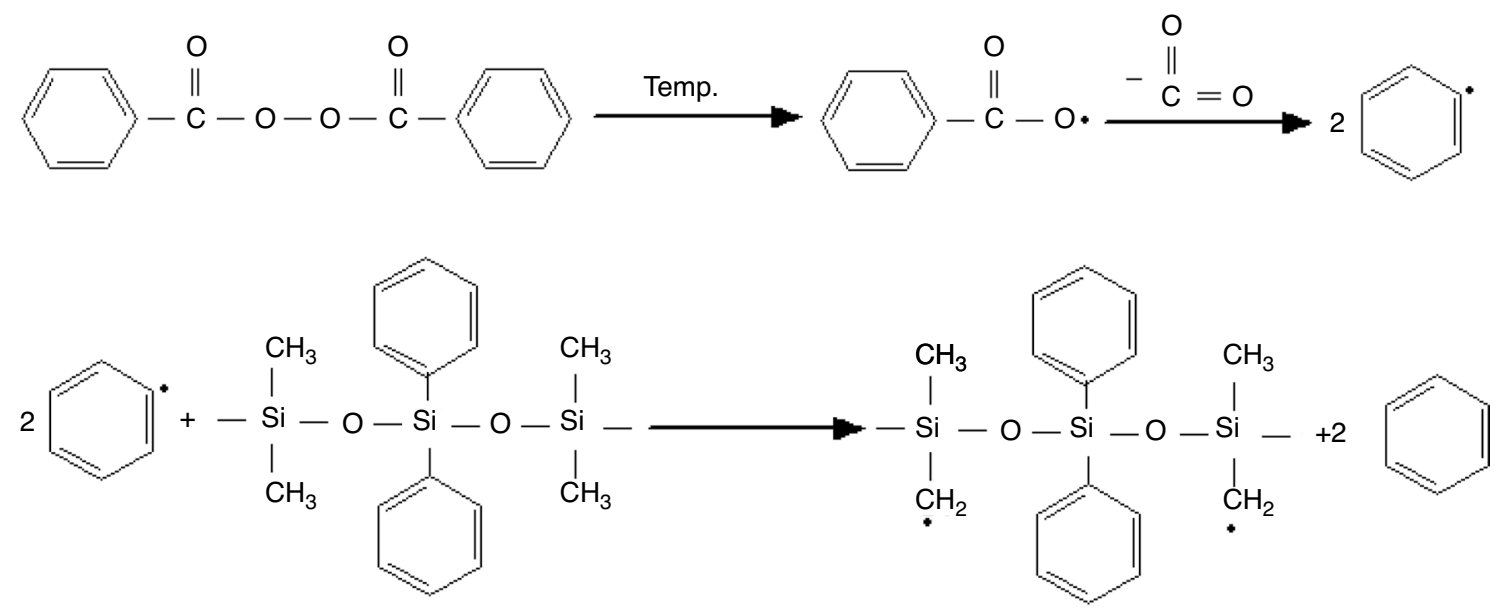<smiles>CO[Si](C)(C)O[Si](C)(C)O[Si](C)(C)O[Si](C)(CC[Si](C)(OC)O[Si](C)(C)OC)OC</smiles>

Fig. 1 Thermal crosslinking according to the radical mechanism 
The target of this work was to prepare and test the samples of single-side self-adhesive tapes from silicone pressuresensitive composition with kaolin. Mechanical properties and thermal resistance of obtained single-side self-adhesive tapes were significantly improved. In the available literature, there are no reports about single-side tapes based on silicone PSAs containing kaolin. In addition, the presence of kaolin also affects non-flammability and plasticity. The literature shows that kaolin also has a positive effect on mechanical properties, while the most important self-adhesive properties (tack, adhesion, and shrinkage) are presented in this paper.

This work uses a kaolin-BASF product under the trade name Mattex MX. It is one of the structural pigments that combines whiteness with low sheen and high tint strength. The particle size is $1.1 \mu \mathrm{m}$ and the brightness is $90 \%$. Manufacturers suggest using this commodity mainly for coatings. In the presented research, we managed to use this product to modify pressure-sensitive adhesives, examining how it will affect the measured properties.

\section{Experimental}

\section{Materials}

In this work, two commercially available silicone adhesives were used (DOWSIL ${ }^{\mathrm{TM}}$ Q2-7566 and DOWSIL ${ }^{\mathrm{TM}}$ 282), the products of Dow Corning (USA). Dichlorobenzoyl peroxide (DClBPO) was used as a crosslinking agent. The peroxide was a product of Peroxid-Chemie (Germany). Kaolin MATTEX® MX (BASF Germany) was used as a filler.

\section{Preparation of one-side tape on silicone pressure-sensitive adhesives with kaolin}

The silicone PSA was mixed with a crosslinking agent to prepare homogeneous composition containing 50 mass\% of polymer (with the appropriate amount of 2, 4-dichlorobenzoyl peroxide (DClBPO) in accordance with Table 1). The toluene was used as a solvent. The concentration of crosslinking compound was selected on the basis of previous research and literature. Composition was mixed with filler (kaolin) to obtain homogeneous consistence (depending on

Table 1 The amount of crosslinking compound depending on the adhesives resin

\begin{tabular}{ll}
\hline Adhesive & $\begin{array}{l}\text { Crosslinking } \\
\text { agent content/ } \\
\text { mass\%* }\end{array}$ \\
\hline DOWSIL $^{\text {TM } 282}$ & 2.5 \\
DOWSIL $^{\text {TM }}$ Q2-7566 & 1.5 \\
\hline
\end{tabular}

*Mass\% on a base of polymer content the composition 1, 3, 5 or 7 mass\% on a basis of polymer content). Subsequently, the composition was coated on polyester film $(36 \mu \mathrm{m})$, with coat speed of $5 \mathrm{~cm} / \mathrm{s}$ and dried for 10 min at $110^{\circ} \mathrm{C}$ in drying canal. The adhesive basis mass was $45 \mathrm{~g} \mathrm{~m}^{-2}$. The obtained adhesive film was protected by a second polyester film $(36 \mu \mathrm{m})$ as a cover layer. One-side tapes were used for further tests, i.e., peel adhesion, tack, shear strength, and shrinkage.

\section{Methods}

The value of peel adhesion of Si-PSA was measured according to the standard AFERA 4001 developed by Association des Fabricants Europeens de Rubans Auto-Adhesifs. The testing machine Zwick/Roell Z010 (Zwick/ Roell, Germany) was used for the tests. The strip of Si-PSA tape $(2.5 \mathrm{~cm} \times 17.5 \mathrm{~cm} / \mathrm{ca} 1 \mathrm{in} \mathrm{x}$ ca 7 in) has been applied on a degreased steel plate with at least $15 \mathrm{~cm}^{2}$ of contact area between the plate and the tape. After applying to the plate, the contact surface was tightened with a $2 \mathrm{~kg}$ rubber roller to improve the wettability of the tape. After that, the plate was mounted in the lower jaws of testing machine, and the end of the sample strip in the upper jaws in the way that the jaws and the sample forms $90^{\circ}$ angle. During the test, the lower jaws remain static and the upper jaws are moving up at a constant speed of $300 \mathrm{~mm} \mathrm{~min}^{-1}$. The value of the average force needed to tear off the belt from the metal plate gives the result of peel adhesion test. The values presented in the article are the average of three measurements $[3,9,18]$.

The tack of Si-PSA was measured according to the standard AFERA 4015 developed by Association des Fabricants Europeens de Rubans Auto-Adhesifs, using the same test machine Zwick/Roell Z010. The one-sided pressure-sensitive adhesive film, with dimensions $175 \mathrm{~mm} \times 25 \mathrm{~mm}$, was placed in the upper jaws with an adhesive side to the outside, so as to form a loop. The sample loop is dropped at a speed of $100 \mathrm{~mm} \mathrm{~min}^{-1}$ onto a steel plate placed at an angle of $90^{\circ}$ horizontally in the machine's lower jaws. The contact surface area is ca $5 \mathrm{~cm}^{2}(2.5 \mathrm{~cm} \times 2 \mathrm{~cm})$. After the contact of the sample strip with the plate without additional force, the tape loop is moved up to tear off. The result of the tack test is the value of the force required to detach the tape from the plate $[9,19]$.

The shear strength (cohesion) of Si-PSA was measured in accordance with the standard FTM-8 FINAT using test machine designed at the International Laboratory of Adhesives and Self-Adhesive Materials of the West Pomeranian University of Technology in Szczecin. The one-sided adhesive film was attached to a degreased steel plate and pressed with a $2 \mathrm{~kg}$ rubber roller. The contact surface area of SiPSA film sample was $6.25 \mathrm{~cm}^{2}(2.5 \mathrm{~cm} \times 2.5 \mathrm{~cm})$. The plate was then placed in the test machine, and the free end of the test sample was loaded with a $1 \mathrm{~kg}$ load, such that the 
direction of the pulling force was parallel to the surface of the joint (the shear force). The test machine automatically measured the time at which the sample of the adhesive tape would detach from the metal plate. The cohesion value was measured at two levels of temperatures $20^{\circ} \mathrm{C}$ and $70{ }^{\circ} \mathrm{C}[3$, $9,18]$ and as expressed temperature $\left({ }^{\circ} \mathrm{C}\right)$ elapsing between the moment burden on the sample until to cohesion/adhesion crack.

The value of shrinkage was measured using the wellknown cross-method. The PVC or PET film was coated with a sample Si-PSA layer and cross-linked. Then it was applied on a degreased metal plate and two cuts were made at the right angle. The width of the cuts was measured. The measurements were taken at given time intervals, up to 42 days, at a measuring temperature of $70{ }^{\circ} \mathrm{C}$. The shrinkage is the percentage value of the ratios of width of the cuts. The shrinkage greater than $0.5 \%$ is not allowed [20,21].

The testing of the stability of silicon adhesives containing kaolin over time was determined by reference to the change in viscosity of prepared silicone adhesives containing different filler contents. Viscosity measurements were made with a Brookfield viscometer at room temperature at intervals, respectively, immediately after mixing and after 1, 2, 3, 5, 7, 36, 60, and 90 days [3, 19].

Reactivity studies between the crosslinking agent and the silicone adhesive during the crosslinking process were carried out for selected compositions. Thermal effects of the crosslinking process at increased temperature were tested using differential scanning calorimetry (DSC) Q100 DSC from TA Instruments. The measurement was carried out in a cycle heating-cooling-heating in the temperature range from -90 to $250{ }^{\circ} \mathrm{C}$ [22].

Thermal stability of silicone pressure-sensitive adhesives compositions was assessed by thermogravimetry (TGA) using TGA 2950 TA Instruments Inc. unit interfaced with the control unit Thermal Analyst 2100 (TA Instruments). All samples about ca. $10 \mathrm{mg}$. were contained in a platinum crucible and the TGA cell was blown through with oxygen at $60 \mathrm{~mL} \mathrm{~min}^{-1}$ during degradation process. The temperature was increased at the rate of $5^{\circ} \mathrm{C} \mathrm{min}^{-1}[22,23]$.

The studies of flammability were carried out for the selected silicone pressure-sensitive adhesive samples, determining the rate of heat and smoke release using a cone calorimeter. The tests were made in accordance with the standard ISO 5660-1:2015 (Fire test. Reaction to fire. Heat release, smoke release and mass loss rate). The determination of the rate of heat and smoke emitted from the test samples in a cone calorimeter is based on the measurement of oxygen consumed, which is necessary for the combustion process. As a result of supported observations, it is assumed that for each $1 \mathrm{~kg}$ of oxygen consumed $13.1 \mathrm{MJ}$ of energy is obtained. For the tests, horizontally arranged samples $(10 \mathrm{~cm} \times 10 \mathrm{~cm})$ were used, which were heated with a $30 \mathrm{~kW} \mathrm{~m}^{-2}$ heat stream emitted from the conical radiator, thus imitating the first phase of fire development. The gases emitted during the decomposition of the samples were ignited by the igniter. Then, the exhaust gases as a result of the flow forced by the fan were collected by the hood and flow through the chimney, where they were taken by the gas sampling probe and subjected to analysis [24].

The heat of combustion of selected Si-PSAs was also determined according to standard PN-EN 1716:2010 (Reaction to fire test for construction products. Determination of the heat of combustion.) Determination of the heat of combustion consisted in burning a given sample of adhesives film in a calorimetric bomb in an atmosphere of oxygen under pressure and measuring the increase of water temperature in the calorimetric vessel. The ignition stimulus was a glowing ignition wire [20,25].

\section{Results and discussion}

To investigate the influence of kaolin addition on the properties of Si-PSA, the "pure" compositions were selected (Si-PSA without filler), which exhibit the best physical properties such as peel adhesion (for different substrates), tack, shear strength and shrinkage. The choice was based on previous research by the authors [2, 9, 19]. The most important functional properties are summarized in Table 2. The pressure-sensitive adhesives used, without modification, show satisfactory properties. According to the guidelines suggested by the tape manufacturers, they meet the requirements for single-sided adhesive tapes in terms of selfadhesive properties (tack $>8 \mathrm{~N}$, adhesion $>10 \mathrm{~N}$, cohesion $>72 \mathrm{~h}$, shrinkage $>0.5 \%$ ). In the case of thermal resistance, these tapes are only suitable for certain applications. Therefore, they were modified [26].

In the case of both resins tested, already, a small addition of kaolin causes an increase in the viscosity of the tested
Table 2 Basic application properties of silicone pressuresensitive adhesives without filler

\begin{tabular}{lllllll}
\hline Adhesive & $\begin{array}{l}\text { Viscosity after } \\
90 \text { days } \\
{[\mathrm{mPas}]}\end{array}$ & $\begin{array}{l}\text { Peel adhesion } \\
{[\mathrm{N} / 25 \mathrm{~mm}]}\end{array}$ & $\begin{array}{l}\text { Shear strength }[\mathrm{h}] \\
\end{array}$ & $\begin{array}{l}20{ }^{\circ} \mathrm{C} \\
70{ }^{\circ} \mathrm{C}\end{array}$ & $\begin{array}{l}\text { Temp. } \\
\text { resistance } /{ }^{\circ} \mathrm{C}\end{array}$ & Tack [N] \\
\hline $\begin{array}{l}\text { DOWSIL } \\
\text { Q2-7566 }\end{array}$ & 22,250 & 12.5 & $>72$ & $>72$ & 108.6 & 8.5 \\
$\begin{array}{l}\text { DOWSIL } \\
\text { TM } 282\end{array}$ & 32,300 & 12.2 & $>72$ & $>72$ & 133.2 & 19.6 \\
\hline
\end{tabular}


compositions. The tests carried out showed that kaolin-containing compositions are not suitable for long-term storage and in industry they must be obtained "on a current basis" as needed. In most cases, after 3 days, an increase in viscosity was found preventing the measurement (Table 3 ). The increase in adhesive viscosity over time can be explained by the significant copolymer-kaolin interaction resulting from high surface energy of pure kaolin filler as well as interactions between silicone adhesive and silicate filler [17].

In the case of pressure-sensitive adhesives, the problem of too high viscosity can be overcome, for example by the addition of a solvent which will be evaporated during thermal crosslinking. Another way is to coat the adhesive at higher temperatures, as with hot-melt adhesives [27].

In Fig. 2, the effect of the addition of kaolin on the peel adhesion and tack of silicone pressure-sensitive adhesives Q2-7566 and 282 is presented. As with most powder additives that are not soluble in resins, the self-adhesive properties such as peel adhesion and tack of PSA are gradually deteriorated as the amount of filler in the composition increases. In the case of using fillers in the pressure-sensitive adhesives technology, most of the literature reports are observed about the use of coal in various forms (carbon black, nanotubes). Research results also confirm these dependencies [28, 29].

In the case of presented research, the highest level of filling exceeded the lower limit value of these properties (adhesion $>10 \mathrm{~N} / 25 \mathrm{~mm}$; tack $>8 \mathrm{~N}$ [9]), so tapes made of them could not be used in industry due to insufficient adhesion to the substrate despite meeting the appropriate internal strength.

The addition of the filler did not influence the shear strength of pressure-sensitive adhesives, but increased the thermal resistance of the adhesive films tested significantly (Table 4). This effect was particularly visible when the value of $3 \%$ by mass filler was exceeded, at which the

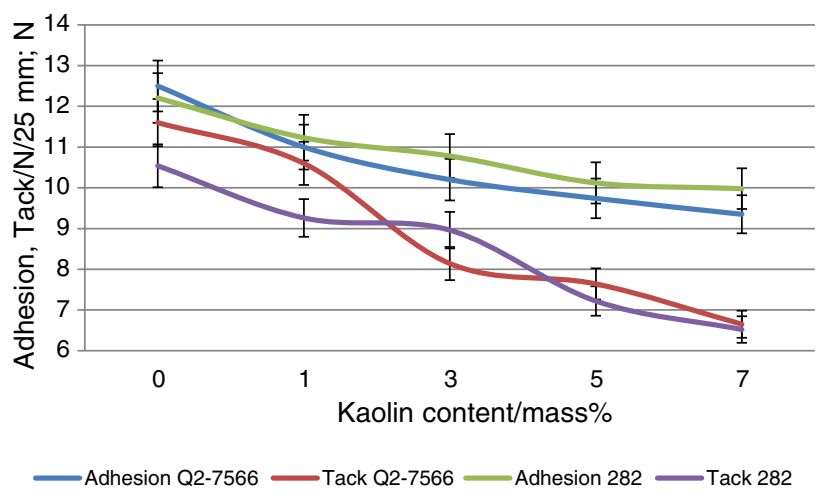

Fig. 2 Influence of kaolin addition on adhesion and tack silicone pressure-sensitive adhesive

adhesive failure occurred at $184^{\circ} \mathrm{C}$ and $222^{\circ} \mathrm{C}$, respectively, for adhesive compositions based on DOWSIL 282 and DOWSIL $^{\text {TM }}$ Q2-7566. The highest value of thermal resistance was demonstrated by a sample of Si-PSA Q2-7566 containing 5 mass\% kaolin (about $226^{\circ} \mathrm{C}$ ). High temperature resistance is a very desirable phenomenon in the technology of obtaining adhesive tapes. When fillers are used, this increase is quite common [30].

Figures 3 and 4 show the influence of kaolin on the shrinkage of silicone pressure-sensitive adhesives. For all the samples tested, the shrinkage value stabilized after 7 days and was maintained until the end of the study (42 days). In pressure-sensitive adhesives technology, the adhesive shrinkage should not exceed $0.5 \%$. The starting, unmodified PSA is within this value, while the smallest shrinkage of the adhesive is most desirable [31]. Small addition of filler already, smaller shrinkage value. A shrinkage of $0.05 \%$ is observed for the two adhesives tested at the highest concentration of kaolin, which confirms the high thermal stability of adhesives with the addition of kaolin.
Table 3 Influence of kaolin concentration on the viscosity of silicone pressure-sensitive adhesives

\begin{tabular}{|c|c|c|c|c|c|c|c|c|c|}
\hline \multirow[t]{2}{*}{ Adhesive } & \multirow{2}{*}{$\begin{array}{l}\text { Filler } \\
\text { content/ } \\
\text { mass \% }\end{array}$} & \multicolumn{8}{|c|}{ Viscosity [mPas] } \\
\hline & & 1 & 2 & 3 & 5 & 7 & 36 & 60 & 90 \\
\hline \multirow[t]{5}{*}{ DOWSIL $^{\text {TM }}$ Q2-7566 } & 0 & 22,250 & 22,250 & 22,250 & 22,250 & 22,250 & 22,250 & 22,250 & 22,250 \\
\hline & 1 & 42,100 & 44,215 & 46,267 & 48,000 & N/A & N/A & N/A & N/A \\
\hline & 3 & 59,600 & N/A & N/A & N/A & N/A & N/A & N/A & N/A \\
\hline & 5 & 60,600 & N/A & N/A & N/A & N/A & N/A & N/A & N/A \\
\hline & 7 & 68,600 & N/A & N/A & N/A & N/A & N/A & N/A & N/A \\
\hline \multirow[t]{5}{*}{ DOWSIL ${ }^{\text {TM }} 282$} & 0 & 32,300 & 32,300 & 32,300 & 32,300 & 32,300 & 32,300 & 32,300 & 32,300 \\
\hline & 1 & 43,450 & 51,236 & 55,236 & N/A & N/A & N/A & N/A & N/A \\
\hline & 3 & 60,126 & N/A & N/A & N/A & N/A & N/A & N/A & N/A \\
\hline & 5 & 61,233 & N/A & N/A & N/A & N/A & N/A & N/A & N/A \\
\hline & 7 & 69,500 & N/A & N/A & N/A & N/A & N/A & N/A & N/A \\
\hline
\end{tabular}

N/A-to high viscosity to measurements 
Table 4 The shear strength (cohesion) at $20^{\circ} \mathrm{C}$ and $70^{\circ} \mathrm{C}$, expressed as a time (h) and temperature $\left({ }^{\circ} \mathrm{C}\right)$ elapsing between the moment burden on the sample until to cohesion/ adhesion failure of one-side tape based on Si-PSA with kaolin filler

\begin{tabular}{|c|c|c|c|c|c|c|}
\hline \multirow{3}{*}{$\begin{array}{l}\text { Filler content/ } \\
\text { mass } \%\end{array}$} & \multicolumn{3}{|c|}{ DOWSIL $^{\text {TM }}$ Q2-7566 } & \multicolumn{3}{|c|}{ DOWSIL ${ }^{\mathrm{TM}} 282$} \\
\hline & \multicolumn{2}{|c|}{ Cohesion [h] } & \multirow{2}{*}{$\begin{array}{l}\text { Temp. } \\
\text { resistance } /{ }^{\circ} \mathrm{C}\end{array}$} & \multicolumn{2}{|c|}{ Cohesion $[\mathrm{h}]$} & \multirow{2}{*}{$\begin{array}{l}\text { Temp. } \\
\text { resistance } /{ }^{\circ} \mathrm{C}\end{array}$} \\
\hline & $20^{\circ} \mathrm{C}$ & $70^{\circ} \mathrm{C}$ & & $20^{\circ} \mathrm{C}$ & $70^{\circ} \mathrm{C}$ & \\
\hline 0 & $>72$ & $>72$ & 133.2 & $>72$ & $>72$ & 108.6 \\
\hline 1 & $>72$ & $>72$ & 146.5 & $>72$ & $>72$ & 145.7 \\
\hline 3 & $>72$ & $>72$ & 222.5 & $>72$ & $>72$ & 184.2 \\
\hline 5 & $>72$ & $>72$ & 225.5 & $>72$ & $>72$ & 201.6 \\
\hline 7 & $>72$ & $>72$ & 219.8 & $>72$ & $>72$ & 205.1 \\
\hline
\end{tabular}

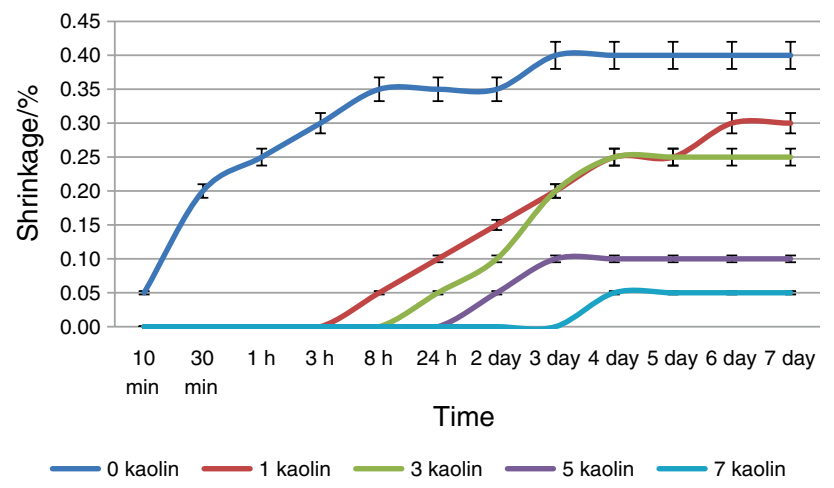

Fig. 3 Influence of kaolin addition on shrinkage silicone pressuresensitive adhesive Q2-7566

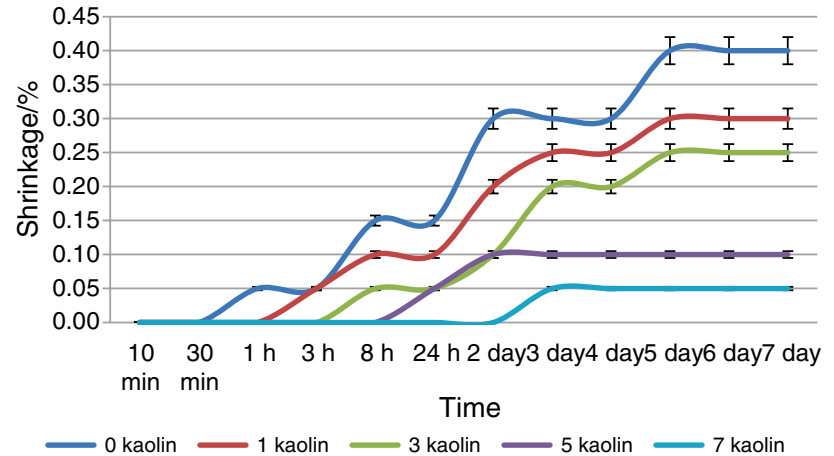

Fig. 4 Influence of kaolin addition on shrinkage silicone pressuresensitive adhesive 282

Figure 5 shows DSC curves for sample Q2-7566 without kaolin and with its different content. As can be seen, the kaolin-free curve has a completely different course to those containing higher concentrations than $1 \%$ of the filler. It can be expected from preliminary studies that the curve containing $1 \%$ kaolin has the most similar course to the original sample (without kaolin). Table 5 gives the exothermic energy values and the maximum temperature that was observed during the first heating of the sample. The energy separated from the system increases as the amount

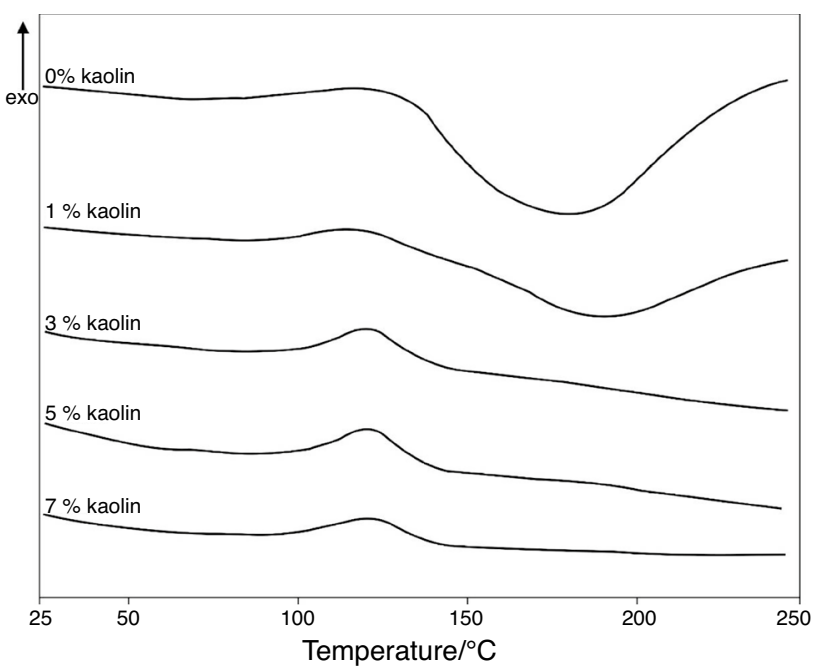

Fig. 5 DSC curves-first heating-sample Q2-7566 with different content of kaolin

Table 5 Influence addition kaolin on exothermic crosslinking reaction Q2-7566 adhesives composition

\begin{tabular}{lll}
\hline Kaolin content/mass\% & Exothermic energy $/ \mathrm{J} \mathrm{g}^{-1}$ & $\begin{array}{l}\text { Maximum } \\
\text { temp. } /{ }^{\circ} \mathrm{C}\end{array}$ \\
\hline 0 & 2.47 & 120.6 \\
1 & 3.21 & 120.1 \\
3 & 4.51 & 121.0 \\
5 & 5.78 & 121.0 \\
7 & 4.04 & 121.6 \\
\hline
\end{tabular}

of filler that is used increases to $5 \%$, then decreases in the case of the addition of $7 \%$ kaolin. This is probably due to the formation of kaolin agglomerates above a concentration of $5 \%$. One of the fundamental parameters of hybrid organic-inorganic compositions is the degree of dispersion of inorganic filler in polymer matrix. Below this concentration, there is an ideal filler dispersion in the polymer matrix, while the above agglomerates disturb this system and change the properties of the composition. 
The maximum temperature, in turn, increases as the kaolin content in the sample increases. Composition Q2-7566 with 5 mass\%. Filler exhibiting the best useful properties; therefore, resin-based Q2-7566 compositions have been used in other measurements.

Composition containing 5 mass\% kaolin has the best properties out of the obtained adhesive compositions. Flammability and combustion tests were performed for the said sample.

In Figs. 6 and 7, TG curve and derivative of mass change after temperature obtained during thermogravimetric analysis in the air atmosphere for sample composition Q2-7566 without and with kaolin at heating rate $10{ }^{\circ} \mathrm{C} \mathrm{min}{ }^{-1}$ were presented. The addition of kaolin to the Q2-7566 composition increased the onset of pyrolysis by about $10^{\circ} \mathrm{C}$ (from 289 to $297^{\circ} \mathrm{C}$ ) and the maximum mass speed temperature by about $60^{\circ} \mathrm{C}$ (from 455 to $515^{\circ} \mathrm{C}$ ). In addition, the maximum mass loss rate increased from 3.13 to $4.76 \% \mathrm{~min}^{-1}$ and the mass of pyrolysis residue from about 55 to $59 \%$ (which is directly related to the increase in the amount of inorganic compounds in the composition by the addition of kaolin). These changes confirm the effect of the addition of kaolin on improving the thermal resistance of the composition and adhesive film.

It was observed that the smallest value $\mathrm{HRR}_{\max }$, which significantly affects the development of fire (Heat Release Rate $\left[\mathrm{kW} \mathrm{m}^{-2}\right]$ ), was obtained by the adhesive composition containing kaolin $\left(51 \mathrm{~kW} \mathrm{~m}^{-2}\right)$. The addition of kaolin significantly reduced $\mathrm{HRR}_{\max }$, completely released heat (THR), and smoke production. In addition, the time required for ignition slightly increased and the amount of produced $\mathrm{CO}$ and $\mathrm{CO}_{2}$ (Table 6).

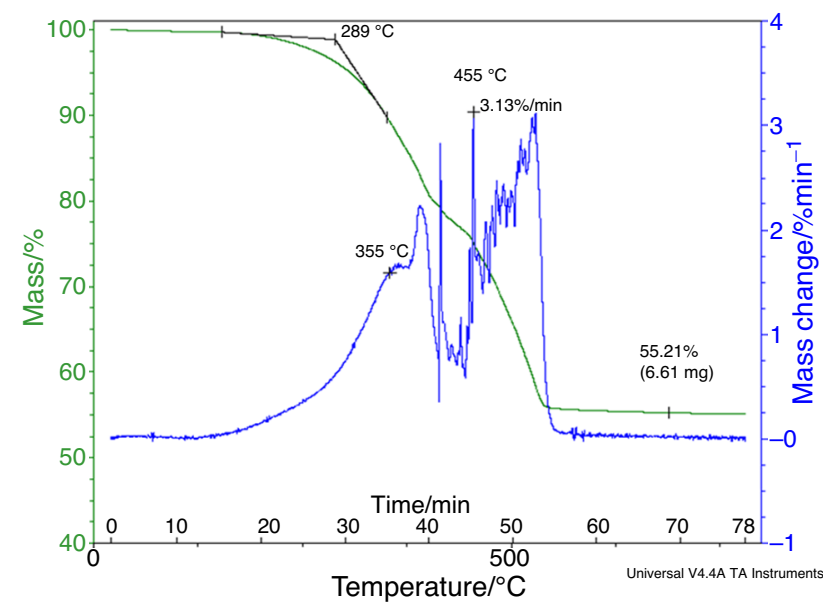

Fig. 6 TG curve and derivative of mass change after temperature obtained during thermogravimetric analysis in air atmosphere for sample composition Q2-7566 at heating rate $10{ }^{\circ} \mathrm{C} \mathrm{min}^{-1}$

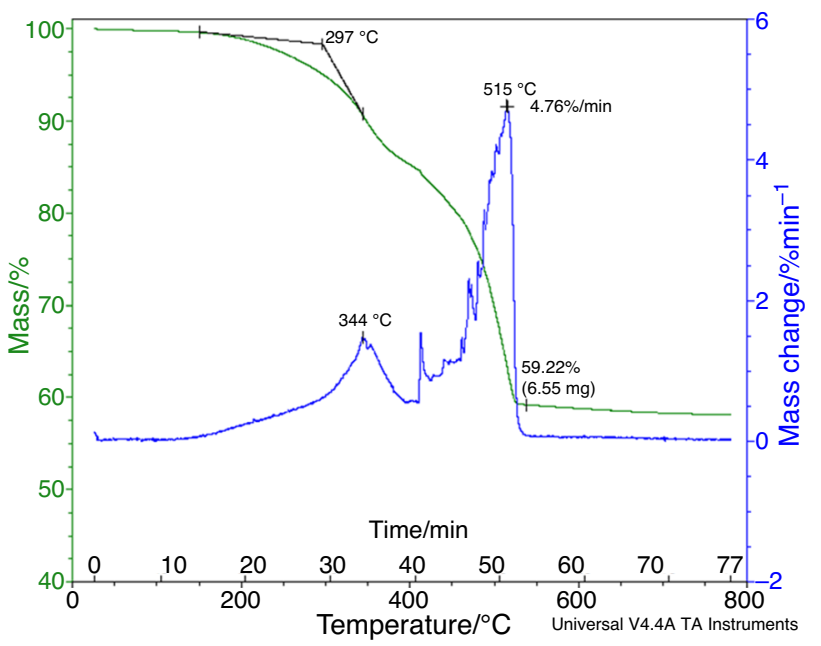

Fig. 7 TG curve and derivative of mass change after temperature obtained during thermogravimetric analysis in air atmosphere for sample composition Q2-7566 with 5 mass\% of kaolin at heating rate $10{ }^{\circ} \mathrm{C} \mathrm{min}-1$

Table 6 The results of testing the selected Si-PSA compositions using a conical calorimeter

\begin{tabular}{|c|c|c|}
\hline \multirow{2}{*}{$\begin{array}{l}\text { Adhesive composition } \\
\text { Kaolin addition/mass\% }\end{array}$} & \multicolumn{2}{|c|}{$Q 2-7566$} \\
\hline & 0 & 5 \\
\hline $\mathrm{HRR}_{\max } / \mathrm{kW} \mathrm{m}^{-2}$ & 119 & 51 \\
\hline MAHRE/kW m & 13 & 16 \\
\hline $\mathrm{THR} / \mathrm{kW} \mathrm{m}^{-2}$ & 1.8 & 1.2 \\
\hline The total amount of smoke $/ \mathrm{m}^{-3}$ & 1.1 & 0.8 \\
\hline $\mathrm{CO}$ emissions $/ \mathrm{mg} \mathrm{g}^{-1}$ & 17.7 & 20.1 \\
\hline $\mathrm{CO}_{2}$ emissions $/ \mathrm{mg} \mathrm{g}^{-1}$ & 98.1 & 109.3 \\
\hline Ignition time $/ \mathrm{t}_{\mathrm{ig}}, \mathrm{s}^{-1}$ & 22 & 28 \\
\hline Heat of combustion $/ \mathrm{kJ} \mathrm{g}^{-1}$ & 18.9 & 18.0 \\
\hline
\end{tabular}

HRRmax-Heat release rate; MAHRE-Maximum average rate of heat emission; THR-Total heat released

\section{Conclusions}

The influence of kaolin addition on the functional properties of selected silicone pressure-sensitive adhesives was investigated. As the concentration of the filler (kaolin) increases in the adhesive composition, the adhesive properties and adhesion slightly decrease. In contrast, the values of shear strength do not change during the modification with kaolin. The single-sided adhesive tapes produced from them are characterized by very high internal strength, regardless of the filler concentration used. The shrinkage of pressure-sensitive adhesives obtained as a result of modification has very low values compared to the initial adhesive. The use of kaolin caused a great improvement in this property. This property is one of the most important properties for the potential 
use of the product. It is similar to thermal resistance. The relatively large increase in thermal resistance (about twice) with a small addition of the filler that makes these materials from the industrial point of view can be much more profitable in production and become an alternative to currently produced heat-resistant tapes. The self-adhesive tapes produced could be used wherever high temperatures are necessary. The best properties of all one-sided tapes produced were adhesive containing 5\% kaolin.

It is generally assumed that one-sided adhesives tapes must meet the basic requirements (peel adhesion $>10 \mathrm{~N} / 25 \mathrm{~mm}$; tack $>8 \mathrm{~N} / 25 \mathrm{~mm}$; shear strength $>72 \mathrm{~h}$; shrinkage $>0.5 \%$ ) to be used in the specific industrial conditions [9]. Designed and produced one- and double-sided self-adhesives tapes based on silicone pressure-sensitive adhesives with kaolin composition can find application in heavy industry to combine elements operating at elevated temperatures. For example, in aeronautics or aerospace (bonding solar cells for satellites or space stations), in heating systems for sticking pipes resistant to high temperatures, and more. They can be used wherever bonds resistant to harsh operating conditions are required.

Authors' contributions Adrian Krzysztof Antosik-Conceptualization, Methodology, Writing-Original Draft. Karolina Mozelewska-Investigation, Visualization. Marta Piątek-Hnat-Investigation, Visualization. Zbigniew Czech-Conceptualization, Methodology, Formal analysis. Marcin Bartkowiak-Investigation, Writing-Review \& Editing.

Data availability The raw/processed data required to reproduce these findings cannot be shared at this time as the data also forms part of an ongoing study.

\section{Declarations}

Conflict of interest The authors declare that they have no known competing financial interests or personal relationships that could have appeared to influence the work reported in this paper.

Open Access This article is licensed under a Creative Commons Attribution 4.0 International License, which permits use, sharing, adaptation, distribution and reproduction in any medium or format, as long as you give appropriate credit to the original author(s) and the source, provide a link to the Creative Commons licence, and indicate if changes were made. The images or other third party material in this article are included in the article's Creative Commons licence, unless indicated otherwise in a credit line to the material. If material is not included in the article's Creative Commons licence and your intended use is not permitted by statutory regulation or exceeds the permitted use, you will need to obtain permission directly from the copyright holder. To view a copy of this licence, visit http://creativecommons.org/licenses/by/4.0/.

\section{References}

1. Sun S, Li M, Liu A. A review on mechanical properties of pressure sensitive adhesives. Int J Adhes Adhes Elsevier. 2013;41:98-106.
2. Khan I, Poh BT. Natural rubber-based pressure-sensitive adhesives: a review. J Polym Environ. 2011;19:793-811.

3. Antosik AK, Raganska P, Czech Z. Thermal crosslinking of silicone pressure-sensitive adhesives using organic peroxides. Polimery. 2014;59:792-7.

4. Adams RD, Comyn J, Wake WC. Structural adhesive joints in engineering. 2nd ed. Netherlands: Springer; 1997.

5. Mecham S, Sentman A, Sambasivam M. Amphiphilic silicone copolymers for pressure sensitive adhesive applications. J Appl Polym Sci. 2010;116:3265-70.

6. Sun F, Hu Y, Du H-G. Synthesis and characterization of MQ silicone resins. J Appl Polym Sci. 2012;125:3532-6.

7. Tolia G, Kevin LS. Study of drug release and tablet characteristics of silicone adhesive matrix tablets. Eur J Pharm Biopharm. 2012;82:518-25.

8. Anderson GL, Stanley SD, Young GL, Brown RA, Evans KB, Wurth LA. The effects of silicone contamination on bond performance of various bond systems. J Adhes. 2010;86:1159-77.

9. Czech Z, Butwin A, Głuch U, Kabatc J. Influence of selected photoinitiators on important properties of photoreactive acrylic pressure-sensitive adhesives. J Appl Polym Sci. 2012;123:118-23.

10. Lin SB, Durfee LD, Ekeland RA, McVie J, Schalau GK. Recent advances in silicone pressure-sensitive adhesives. J Adhes Sci Technol. 2007;21:605-23.

11. Zhang J, Luo R, Jiang M, Xiang Q, Li J. The preparation and performance of a novel room-temperature-cured heat-resistant adhesive for ceramic bonding. Mater Sci Eng A Elsevier BV. 2011;528:2952-9.

12. Hasegawa M, Nomura R. Thermal- and solution-processable polyimides based on mellophanic dianhydride and their applications as heat-resistant adhesives for copper-clad laminates. React Funct Polym. 2011;71:109-20.

13. Wang X, Wang J, Wang H. Preparation and performance of a heatresistant organic adhesive obtained via a liquid $\mathrm{SiC}$ precursor. Int J Adhes Adhes. 2012;35:17-20.

14. Wang C, Huang YD, Wang B. Study on heat-resistant property of adhesive/carbon-carbon composites joints. Int J Adhes Adhes. 2006;26:206-11.

15. Utracki LA, Sepehr M, Boccaleri E. Synthetic, layered nanoparticles for polymeric nanocomposites (PNCs). Polym Adv Technol. 2007; 18:1-37.

16. Njuguna J, Pielichowski K, Desai S. Nanofiller-reinforced polymer nanocomposites. Polym Adv Technol. 2008;19:947-59.

17. Zhang B, Chang Z, Li J, Li X, Kan Y, Gao Z. Effect of kaolin content on the performances of kaolin-hybridized soybean meal-based adhesives for wood composites. Compos Part B Eng. 2019;173:106919.

18. Wilpiszewska K, Czech Z. Citric acid modified potato starch films containing microcrystalline cellulose reinforcement-properties and application. Starch-Stärke. 2014;66:660-7.

19. Antosik AK, Czech Z. Effect of the dye amount on physical properties of silicone pressure sensitive adhesives. Przem Chem. 2015;94:43-4.

20. Czech Z, Kowalczyk A, Kabatc J, Świderska J. Photoreactive UVcrosslinkable solvent-free acrylic pressure-sensitive adhesives containing copolymerizable photoinitiators based on benzophenones. Eur Polym J. 2012;48:1446-54.

21. Singh AK, Niyogi UK, Sabharwal S, Kowalczyk A, Czech Z, Mehra DS. Shrinkage studies in electron beam curable polyurethane pressure-sensitive adhesive. J Adhes Sci Technol. 2013;27:1511-24.

22. Sultan M, Atta S, Bhatti HN, Islam A, Jamil T, Bibi I, et al. Synthesis, characterization, and application STUDIES of polyurethane acrylate thermoset coatings: effect of hard segment. Polym Plast Technol Eng. 2017;56:1608-18. 
23. Li P, Wu Y, Zhou Y, Zuo Y. Preparation and characterization of resorcinol-dialdehyde starch-formaldehyde copolycondensation resin adhesive. Int J Biol Macromol. 2019;127:12-7.

24. Gozdek T, Chudzik J, Imiela M, Bielinski DM. The influence of the addition of ionic liquids on the properties of rubber-coated fabrics filled with layered fillers. Polimery. 2019;64:610-7.

25. Kicko-Walczak E, Półka M. Nanokompozyty polimerowe o zmniejszonej palności z udziałem nanoi mikrocząstek retardantów palenia. Synergizm hybrydowych składników modyfikujących osnowy polimerowe. Przem Chem. 2019;98:1088-95.

26. Ebnesajjad S. Handbook of adhesives and surface preparation. Elsevier; 2011.

27. Sweet RP. Hot-melt silicon pressure sensitive adhesives with phenyl-containing siloxane fluid additive and related methods and articles. 1991.

28. Czech Z, Kowalczyk A, Pełech R, Wróbel RJ, Shao L, Bai Y, et al. Using of carbon nanotubes and nano carbon black for electrical conductivity adjustment of pressure-sensitive adhesives. Int $\mathbf{J}$ Adhes Adhes. 2012;36:20-4.

29. Bessette M, Sankar P. Electrically conductive pressure sensitive adhesives, method of manufacture, and use thereof. 2004.

30. Giannini L, Citterio A, Galimberti M, Cozzi D. Rubber-clay nanocomposites: science, technology and applications. In: Galimberti M, editor. Hoboken. NJ, USA: John Wiley \& Sons, Inc.; 2011.

31. Czech Z. Development in the area of UV-crosslinkable solventbased pressure-sensitive adhesives with excellent shrinkage resistance. Eur Polym J. 2004;40:2221-7.

Publisher's Note Springer Nature remains neutral with regard to jurisdictional claims in published maps and institutional affiliations. 